\title{
Pathology and Rehabilitation of Vinyl and Linoleum Floorings in Health Infrastructures: Statistical Survey
}

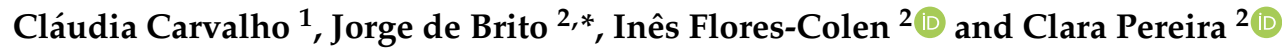 \\ 1 Instituto Superior Técnico, Universidade de Lisboa, Av. Rovisco Pais, 1049-001 Lisbon, Portugal; \\ claudia.m.s.carvalho@ist.utl.pt \\ 2 CERIS, Instituto Superior Técnico, Universidade de Lisboa, Av. Rovisco Pais, 1049-001 Lisbon, Portugal; \\ ines.flores.colen@tecnico.ulisboa.pt (I.F.-C.); clareira@sapo.pt (C.P.) \\ * Correspondence: jb@civil.ist.utl.pt; Tel.: +351-218-497-650
}

Received: 15 April 2019; Accepted: 5 May 2019; Published: 7 May 2019

\begin{abstract}
A statistical survey on the pathology and rehabilitation of linoleum and vinyl floorings is presented. It is based on the visual inspection of 101 vinyl and linoleum floorings, in six health infrastructures in Lisbon, Portugal, which enabled the validation of the classification/nomenclature previously proposed, as well as the corresponding correlation matrices. It was also possible to identify the most common types of anomalies, their probable causes, the most adequate in situ diagnosis methods, and the most useful repair techniques. Anomalies, diagnosis methods, and repair techniques files were also validated. The obtained data enabled anomalies to be related to their causes, in situ diagnosis methods, and respective repair techniques e.g., a high number of scratches/wear were detected associated with dragging of equipment. The conclusions drawn intend to raise awareness among the industry actors and minimize the development of anomalies and their causes at the design and application stages. Furthermore, the main sensitive issues of the cladding system during its service life were revealed, highlighting the importance of a correct maintenance plan to minimize the surface's susceptibility to various degradation mechanisms.
\end{abstract}

Keywords: linoleum and vinyl floorings; inspection; pathology; statistical survey; healthcare infrastructures

\section{Introduction}

Vinyl and linoleum are generally used in floorings and wall claddings. Technological and scientific evolution has played an important role on this type of flooring, allowing the development and marketing of a wide and innovative range of vinyl and linoleum floorings (VLF). It led to an increase in use and a broader scope of application, as well as easier manufacturing and new application methods [1]. In order to obtain better results, the application of VLF must be founded on scientific, physical, and economic criteria. Hence, the choice of flooring should start with an adequate and demanding prescription, based on factors such as the materials' properties, location of the flooring, and the conditions it will be subjected to throughout its service life [2].

The design and execution stages are crucial for the quality of VLF, since, when these stages are not given the proper attention, there is an increase in pathological manifestations and the service life decreases [3]. There is a need to prevent the occurrence of anomalies, along with accurately assessing them, in order to make a correct diagnosis. It is also important to recommend the adequate repair techniques, considering the anomalies' causes. An expert inspection system is the adequate tool to perform these methodological changes in assessment approach and decision-making [4].

However, anomalies that arise in VLF often deny the expectations of a cladding with good performance and durability. In fact, pathological situations in VLF have been occurring more often in the first years in service, showing a direct relation with factors like maintenance, use, and substrate. 
This may be due to the lack of selection criteria for the type of flooring to apply [5], suited to the surrounding environment, allied with the lack of an economic comparative analysis of materials. Tight schedules may also play an important role at the design and execution stages, as well as the lack of training and awareness of non-specialized workmanship, disregard for technical issues, and exclusive consideration of aesthetics. Moreover, the frequent lack of coordination among different designers results in the incompatibility of elements of the prescribed solution (e.g., the adhesion procedure and the substrate) that are only detected at the execution stage.

Therefore, it is of high importance to study the durability of VLF in sets of buildings in various locations, subjected to different actions, in order to understand the pathology according to the characteristics of VLF. Inspections can be systematized and should be included in a maintenance plan, to prevent degradation of the flooring and its substrate.

The American Society for Testing Materials (ASTM) has several publications [6-13] covering distinct aspects, especially in the project and application stages of VLF. The standard tolerances and guides [14-18] from the American Concrete Institute (ACI), should also be taken into account, since the substrate plays such a big role, and it is usually made of concrete. However, apart from these publications, there is hardly any literature (e.g., manuals) regarding the inspection, diagnosis, and rehabilitation in this field. Hence, a system to support the inspection, diagnosis, and repair of VLF was developed by the authors [19].

Regarding the health sector, several studies emphasize the importance of adequate maintenance, in order to prevent hospital-acquired infections [20-30].

The purpose of this paper is thus two-fold, as it intends to show how the expert system of inspection was validated, as well as present and analyze the statistical data acquired during that process.

Finally, though the expert system of inspection was built based on the pathology detected in healthcare facilities, it can be extrapolated to any other facilities (e.g., schools, sports facilities, airports). Still, data on healthcare facilities pathology should not be applied directly for decision-making in other types of facilities. Systems created outside the scope of healthcare cannot be used in healthcare facilities, due to specific criteria that must be considered (e.g., infection control).

\section{Research Significance}

During the inspection campaign, in July 2017, 101 floorings were inspected in six healthcare facilities in the Lisbon area, Portugal; two of them private and four public. These healthcare facilities are representative of health infrastructures in Portugal. Healthcare facilities were chosen as the object of the inspection campaign due to the common use of VLF in this type of facility and to the maintenance specificity of healthcare facilities. Thirteen floorings were of linoleum and 88 of vinyl, influencing the analysis of results. Following the methodology implemented by the same research team in other cladding systems [31-42], the inspections' data enabled the comparison with the theoretical correlation matrices, validating them. The matrices that relate anomalies and causes, anomalies and diagnosis methods, anomalies and repair techniques, and anomalies with each other are presented by Carvalho et al. [19]. Detailed files with information on each type of anomaly, diagnosis method, and repair technique were also created and validated.

After validating the expert inspection system, the inspection data were statistically analyzed, and conclusions were drawn. To the best of the authors' knowledge, there is no other work in the literature with the same scope and objectives considering VLF.

\section{Pathology and Classification System}

The classification of anomalies proposed by Carvalho et al. [19] is divided in three groups, according to the location of the anomaly, and has a total of ten anomalies, listed in Table 1 . The first group includes anomalies on the surface or in depth of the flooring (A-A), the second anomalies that occur on the substrate (A-B), and the third group anomalies on flooring welding joints (A-C). Anomalies are coded with an A for anomaly, a hyphen, and a sequential capital letter for the group 
reference (i.e., A for surface and depth, B for substrate, and C for joints), followed by sequential numbering. The probable causes of anomalies, diagnosis methods, and repair techniques are coded using similar labelling.

Table 1. Proposed classification of flooring anomalies, their probable causes, diagnosis, and rehabilitation techniques [19].

\begin{tabular}{|c|c|c|c|}
\hline Code & Anomaly & Code & Anomaly \\
\hline$A-A$ & on the surface or in depth & A-A4 & prickles/punctures \\
\hline A-A1 & scratches/wear & A-A5 & cracking \\
\hline A-A2 & staining/dirt/color changes & A-A6 & loss/fracture/rotting \\
\hline A-A3 & brightness changes & - & - \\
\hline$A-B$ & on the substrate & A-B2 & peeling \\
\hline A-B1 & blistering & A-B3 & depression/settlement \\
\hline$A-C$ & on the joints & $\mathrm{A}-\mathrm{C} 1$ & faulty welding joints \\
\hline Code & Probable cause & Code & Probable cause \\
\hline$C-A$ & design errors & $\mathrm{C}-\mathrm{A} 3$ & deficient detail of singular areas \\
\hline C-A1 & choice of incompatible or unsuitable materials & C-A4 & defective design of the coating system \\
\hline C-A2 & areas inaccessible for cleaning & - & - \\
\hline$C-B$ & execution errors & C-B4 & inadequate substrate preparation \\
\hline & use of materials not available and/or & & \\
\hline B-B1 & $\begin{array}{l}\text { inadequate and/or incompatible with each } \\
\text { other }\end{array}$ & C-B5 & inadequate application of material \\
\hline C-B2 & $\begin{array}{l}\text { application under extreme environmental } \\
\text { conditions }\end{array}$ & C-B6 & poor interpretation of the project \\
\hline C-B3 & $\begin{array}{l}\text { non-compliance with the pauses the between } \\
\text { the several phases of execution }\end{array}$ & C-B7 & $\begin{array}{l}\text { non-compliance with the setting time until } \\
\text { the use of flooring }\end{array}$ \\
\hline$C-C$ & external mechanical actions & $\mathrm{C}-\mathrm{C} 3$ & substrate deformation \\
\hline $\mathrm{C}-\mathrm{C} 1$ & fall of objects & $\mathrm{C}-\mathrm{C} 4$ & dragging of equipment \\
\hline $\mathrm{C}-\mathrm{C} 2$ & concentration of stress in the substrate & $\mathrm{C}-\mathrm{C} 5$ & punching actions \\
\hline$C-D$ & environmental actions & C-D3 & presence of moisture \\
\hline C-D1 & sun exposure & C-D4 & natural ageing \\
\hline C-D2 & biological action/chemically aggressive agents & - & - \\
\hline$C-E$ & maintenance errors & C-E1 & $\begin{array}{l}\text { insufficient/incorrect cleaning of the } \\
\text { flooring }\end{array}$ \\
\hline$C-F$ & change of the original use conditions & C-F2 & changing the use of space \\
\hline C-F1 & excessive loads & - & - \\
\hline Code & Diagnosis method & Code & Diagnosis method \\
\hline$M-A$ & assisted visual analysis & M-A2 & crack meter (ND) \\
\hline M-A1 & visual inspection (ND) & M-A3 & crack ruler (ND) \\
\hline$M-B$ & mechanical & M-B2 & percussion hammer (ND) \\
\hline M-B1 & sphere impact test (SM) & M-B3 & pull-off adhesion test (D) \\
\hline$M-C$ & thermal & $\mathrm{M}-\mathrm{C} 1$ & infrared thermography (ND) \\
\hline$M-D$ & water content and temperature & M-D3 & hygrometer (ND) \\
\hline M-D1 & $\begin{array}{l}\text { inner moisture and temperature measurement } \\
\text { (ND) }\end{array}$ & M-D4 & speedy moisture test (D) \\
\hline M-D2 & superficial moisture measurement (ND) & - & - \\
\hline Code & Repair techniques & Code & Repair techniques \\
\hline$R-A$ & superficial zones & R-A3 & stripping $\left(^{*}\right)(\mathrm{cr} ; \mathrm{pr} ; \mathrm{m})$ \\
\hline R-A1 & cleaning the cladding $(\mathrm{cr} ; \mathrm{m})$ & R-A4 & $\begin{array}{l}\text { mixture of white glue and linoleum scraps } \\
\left({ }^{*}\right)(\mathrm{cr})\end{array}$ \\
\hline R-A2 & applying a surface protector (cr; pr; m) & R-A5 & application of welding (cr) \\
\hline$R-B$ & whole flooring & R-B2 & partial replacement of the flooring (cr; pr) \\
\hline R-B1 & total replacement of the flooring ( $\mathrm{cr} ; \mathrm{pr}$ ) & R-B3 & glue injection (cr; pr) \\
\hline$R-C$ & substrate & $\mathrm{R}-\mathrm{C} 1$ & replacement of the levelling layer (cr; pr) \\
\hline$R-D$ & flooring surrounding area & R-D1 & repair of anomalies in footers (cr; pr) \\
\hline
\end{tabular}


Carvalho et al. [19] also proposed a classification of probable causes of anomalies, to adequately decide how to control and repair detected anomalies (Table 1). It groups the causes of anomalies in VLF into six categories, organized chronologically: C-A design errors, C-B execution errors, C-C external mechanical actions, C-D environmental actions, C-E maintenance errors, C-F change of the original use conditions. As for the classification of diagnosis methods, it considers the technology used in the tests to group methods. The classification of repair techniques takes the location of the anomaly into account to group the techniques.

\section{VLF Inspection Plan}

Planning of VLF inspections is essential, as inspection and validation forms must be prepared, as well as specific equipment (rulers, measuring equipment, photographic equipment, and other accessories, if necessary). Inspection and validation forms were created based on previous research [39, 41,42]. The scope of the inspection program was to validate the system proposed by Carvalho et al. [19].

\subsection{Inspection Forms}

In order to make VLF inspections more effective, inspection forms were created to characterize the buildings and the materials and procedures related to the flooring's execution. These forms also contain important information on the building's surroundings. Validation forms include data on the detected anomalies and all related data, as well on the VLF areas that should be given special attention in the future.

In each inspection form, the following information should be filled out: In the heading, the number of the inspection form, date, surveyor's name and role, and the inspection's main purpose; for each building, the location, main use, year of construction, location of the floor under analysis, exposure to polluting agents, and solar radiation, and any contacts made; for each inspected flooring, linoleum or vinyl type, type of application (tile or roller), type of glue used, area (in $\mathrm{m}^{2}$ ), type of substrate, existence of a vapor barrier, welding cord, type of finish/skirting (and height), and any singularities of the floor; maintenance operations recorded, namely, type and frequency of maintenance actions, and details about them (date, type of materials, and techniques used).

\subsection{Validation Forms}

For each VLF inspected, one validation form was filled out, in which the detected anomalies were identified according to the classification described in Section 2. It should be noted that the number of anomalies identified in each flooring was always equal to or greater than one, since only VLF with anomalies were considered. Each anomaly is characterized in terms of location within the VLF, affected area or length (nominal and relative), and the degradation of the laying material or the substrate itself. Other data of interest for the characterization of the repair urgency were also collected, such as the aesthetic value of the affected areas and the possible recurrent occurrence.

For each detected anomaly, probable causes (direct or indirect), adequate diagnosis methods, and repair techniques were registered on site, based on visual observation and according to the classification systems mentioned in Section 2.

\section{Data analysis and Statistical Characterization}

As shown in Figure 1, of the 101 VLF inspected, approximately one third was over 20 years, one third was in the remaining age gaps, and the other third did not have information on the construction year (NI). The oldest VLF inspected, of those with a known age, was 32 years old. That flooring was quite worn due to consecutive waxing and stripping. However, it did not show anomalies other than wear, scratching, and welding joints between tiles requiring replacement. According to Gorrée et al. [43], stripping and resealing a linoleum floor should be done six times in 20 years (approximately every three years) in public buildings, but the specificity of the inspected floors may have required a different periodicity of this activity. 


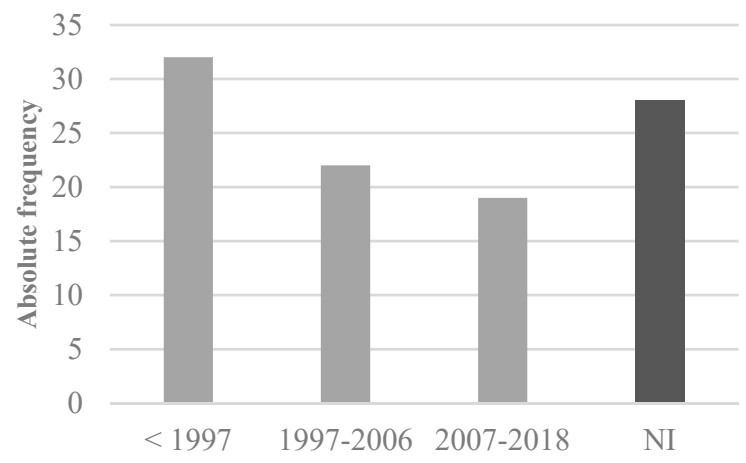

Figure 1. Absolute frequency of the inspected vinyl and linoleum floorings (VLF) according to the construction year (NI-not identified).

Even though the sample's floorings are only divided in vinyl and linoleum materials, as no laboratory tests were performed, nor sufficient information was available, the analysis of the age of the flooring system shows that more recent floorings are likely to have improved materials and application techniques that result from the constant innovation in the sector.

\subsection{Anomalies Observed in the Sample}

A total of 344 anomalies were detected in the inspected floorings, resulting in an average of 3.4 anomalies per flooring. As for the probable causes, 537 were recorded, resulting in an average of approximately 1.6 causes per anomaly. As to diagnosis methods and repair techniques, a total of 898 and 739, respectively, were recommended, which results in an approximate average of 2.6 diagnosis methods and 2.1 repair techniques per anomaly. The absolute and relative frequencies of detected anomalies were analyzed (Figure 2). Note that the relative frequency was calculated by dividing the absolute frequency by the number of inspected VLF.

Anomalies "A-A1 scratches/wear", "A-A2 staining/dirt/color changes", and "A-C1 faulty welding joints" occurred in more than half of the inspected floorings. The most frequent anomaly was A-A1, occurring in 76 floorings. Considering how easy it is to scratch a VLF [1], such frequency is not surprising, as careless dragging of equipment is enough to leave a scratch, and the wheels of most trolleys have inadequate or worn-out material. An even higher frequency could be expected, but it should be noted that recent floorings, with only months of age, were also considered in the inspections campaign.

Anomaly "A-B1 blistering" was the least frequent one (in approximately $10 \%$ of the sample). Nevertheless, it has considerably more severe consequences than others. The low frequency of A-B1 may be associated with its seriousness, since, when blistering occurs, it can condition the mobility of people and equipment, as well as affect the aesthetic value. If it is due to infiltration, the absence of repair actions may aggravate the situation. Thus, it is assumed that, when blistering occurs, it is usually repaired, resulting in a low frequency of the anomaly.

Anomaly A-C1 faulty welding joint is the second most frequent anomaly, occurring in $53 \%$ of floorings. This result may be associated with poor execution, leading to the accumulation of dirt, and fractures in smaller areas, when subjected to stress.

As for anomaly "A-A2 staining/dirt/color changes", 52 occurrences were detected, but a higher frequency was expected, according to the results of Personen-Leinonen et al. [44]. However, since the inspected infrastructures belong to the health sector, they involve very high cleaning requirements, justifying the lower than expected frequency. In general, dirt can be eliminated with cleaning. As for indelible stains and color changes in linoleum floorings, they can only be removed by stripping. In vinyl or recent linoleum floorings, they can be removed by polishing. In these cases, the VLF is only replaced when the affected area is of exceptional aesthetic value. 
Comparing the incidence of anomalies in VLF with that of wood floorings, it is found that, in wood floorings, scratches, or wrinkles (above $80 \%$ of floorings) are also the most common detected anomaly [33]. In wood floorings, scratches are even more predominant, as the next frequent anomaly is only detected in about $25 \%$ of inspected floorings. These results raise the question whether scratching may be a generalized problem of floorings, possibly associated with the inadequate functional classification of space and rooms.

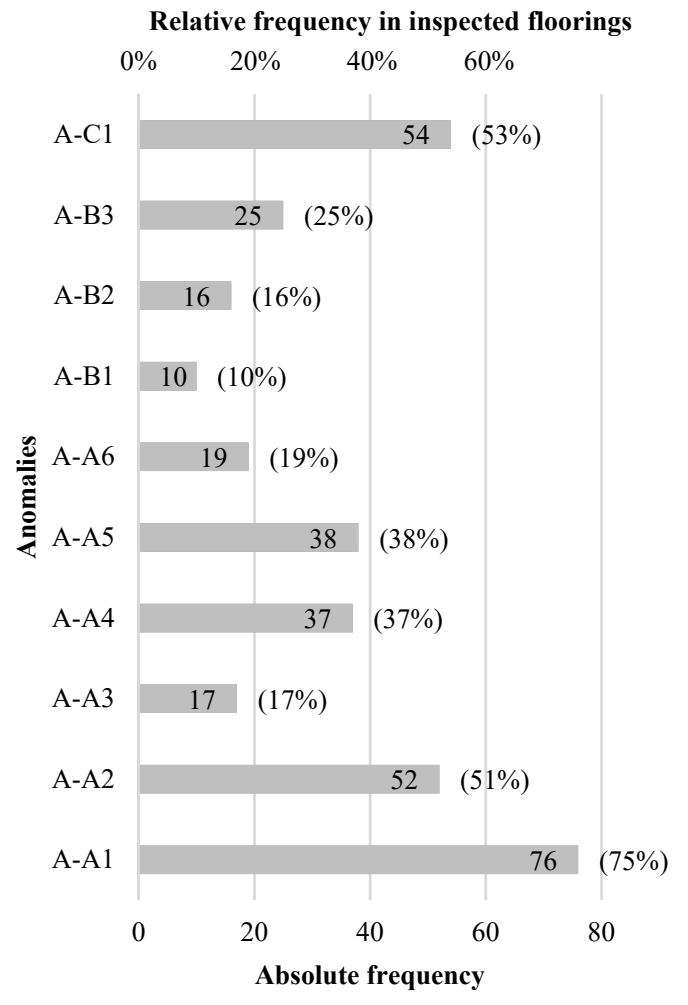

(a)

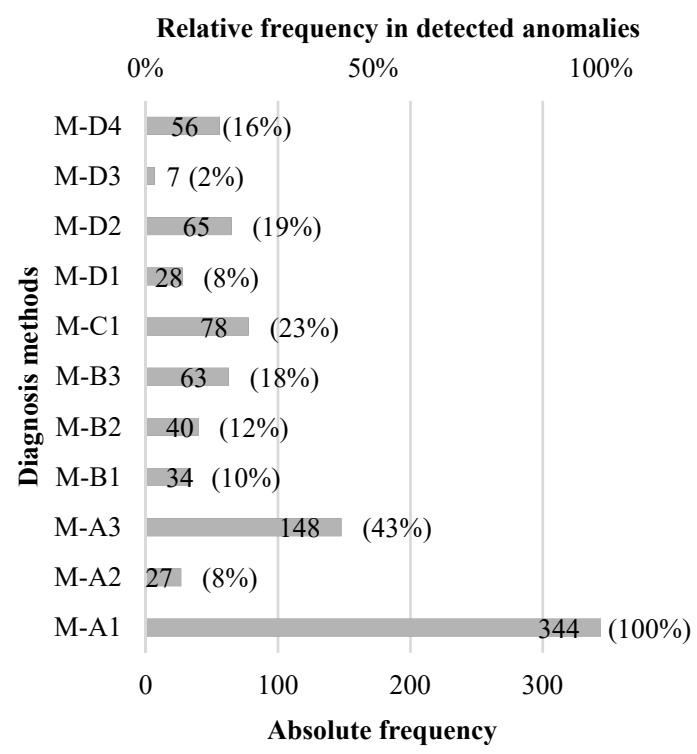

(c)

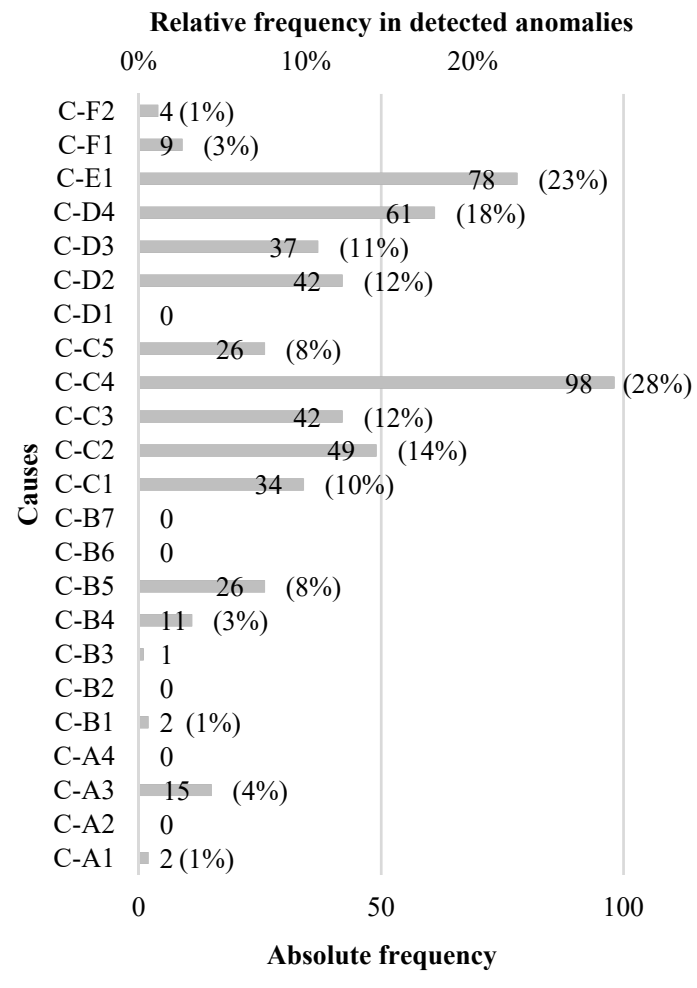

(b)

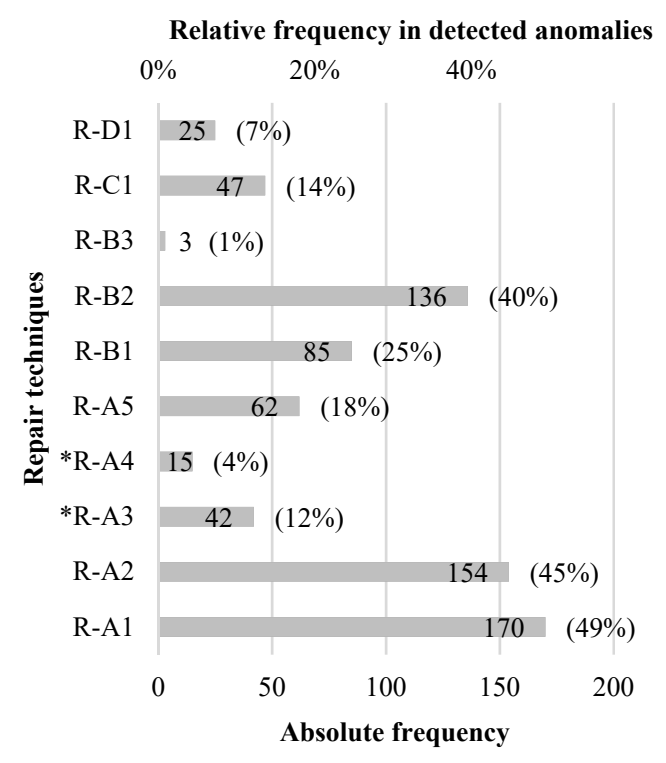

* R-A3 and R-A4 techniques only concern linoleum floorings.

(d)

Figure 2. Absolute frequency (and relative frequency) of: (a) Detected anomalies; (b) probable causes; (c) adequate diagnosis methods; (d) recommended repair techniques. 
In regard to urgency of repair, approximately $47 \%$ of anomalies belong to intervention level 1, $40 \%$ to level 0 (the most urgent), and 13\% to level 2 (Figure 3). Anomalies on the substrate (A-B) usually require a higher repair urgency, as the affected area is prone to rapidly increase. It is also the case of anomalies "A-A5 cracking" and "A-C1 faulty welding joints", if there is a possibility of infiltration. In the health sector, aseptic conditions and functionality must be guaranteed. However, functionality becomes impossible when blistering and depressions occur, as they can un-calibrate instruments and hinder the stability of a patient being transported on a stretcher.

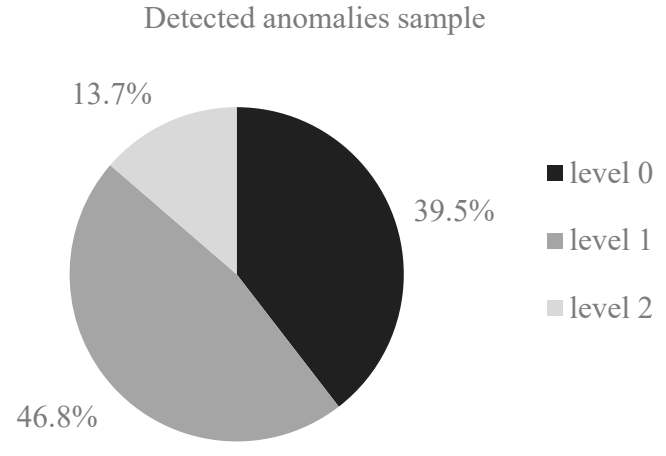

(a)

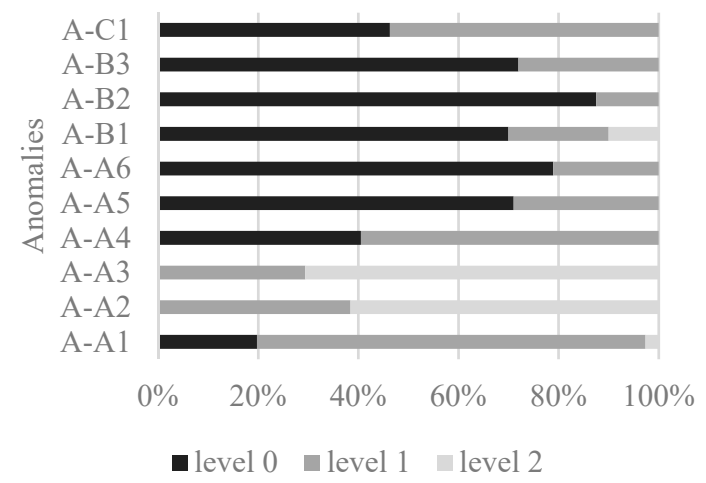

(b)

Figure 3. Urgency of repair: (a) Relative frequency of anomalies in each level; (b) relative frequency of each level for each type of detected anomalies.

Figure 3 shows that the anomalies that most require short-term intervention were, in descending order of priority, "A-B2 peeling" (88\%), "A-A6 loss/fracture/rotting of material" (79\%), "A-B3 depression/settlement" (72\%), "A-A5 cracking" (71\%), and "A-B1 blistering" (70\%). In group A-A anomalies on the surface or in depth, anomalies "A-A4 prickles/punctures" (41\%) and "A-A1 scratches/wear" (20\%) could also be highlighted. As for anomaly "A-C1 faulty welding joints", approximately half of the sample was at level 0 and the other half at level 1 . The absence or deficiency of the welding joint, allied with inadequate cleaning, creates a singularity where water may enter, triggering detachment of the flooring. This shows the importance of timely maintenance interventions at welding joints to guarantee the expected service life of the VLF. Regarding anomalies "A-A2 staining/dirt/color changes" and "A-A3 brightness changes", most belonged to level 2 (less urgent), with $62 \%$ and $71 \%$, respectively. This is related to the mentioned high cleaning requirements in health infrastructures.

As for location of anomalies, in some situations, a specific type of anomaly is predominant. It is the case of anomaly "A-A1 scratches/wear", which is often seen in poorly executed transition areas or at the entrance of the rooms (Figure 4a,b). It is also the case of anomaly "A-A3 brightness changes", which often occurs immediately below the alcohol-based disinfectant dispensers (Figure 4c).

As mentioned, out of the six inspected health infrastructures, two were private and four were public, resulting in 24 and 77 analyzed floorings, respectively. Thus, a comparison between anomalies in private and public infrastructures was made. First of all, a significant age difference was noted, as all VLF inspected in Private-1 were more than 20 years old, while those in Private-2 were up to 10 years old. The frequency of anomalies in Private-1 (12 cases), Private-2 (12 cases), and the inspected Public sector facilities (77 cases) is shown in Figure 5. 


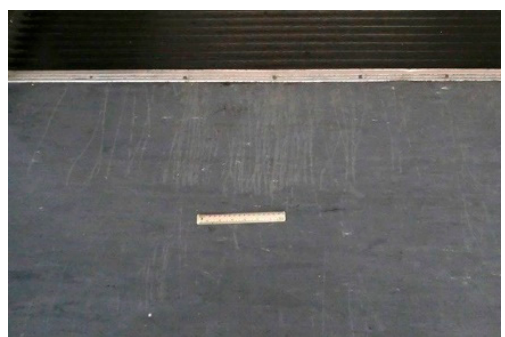

(a)

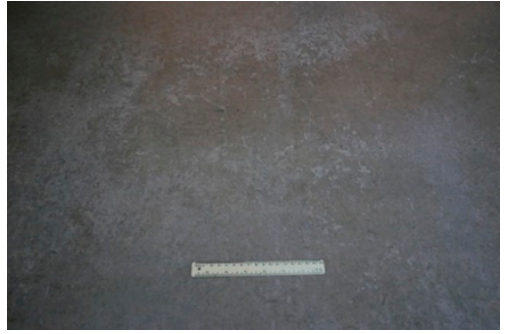

(d)

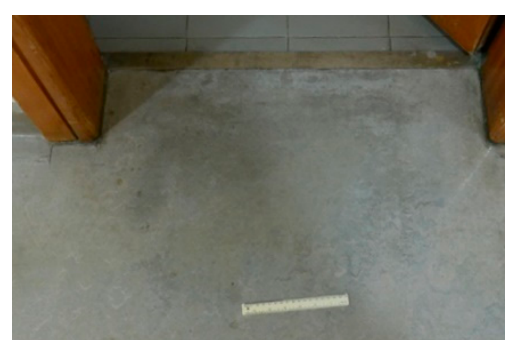

(b)

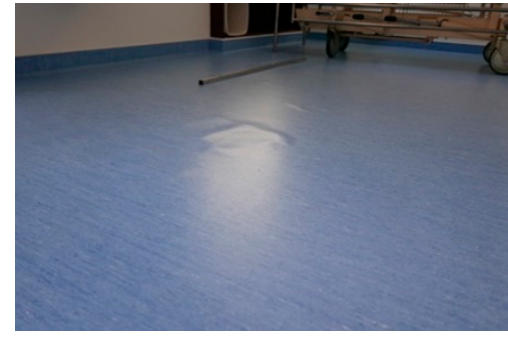

(e)

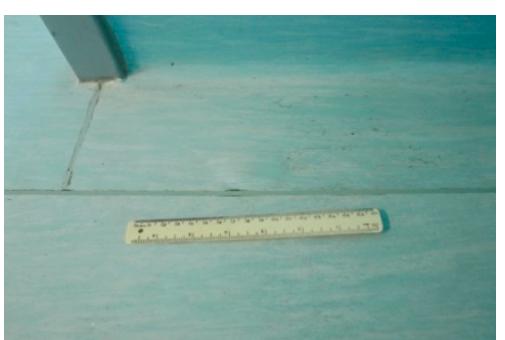

(c)

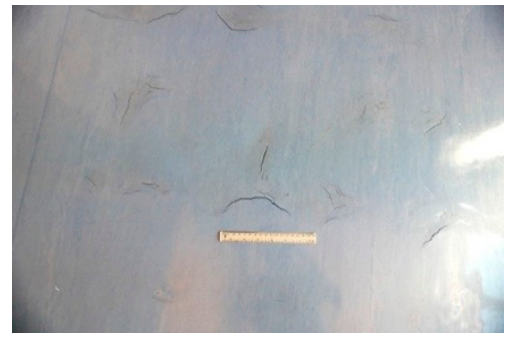

(f)

Figure 4. Anomalies: (a) A-A1 scratches; (b) A-A1 wear; (c) A-A3 brightness changes; (d) A-A3 brightness changes on a linoleum flooring due to an inadequate maintenance; (e) A-B2 peeling, requiring the use of repair technique R-B2 partial replacement; (f) A-B3 depression/settlement, requiring the use of repair technique R-B1 total replacement.

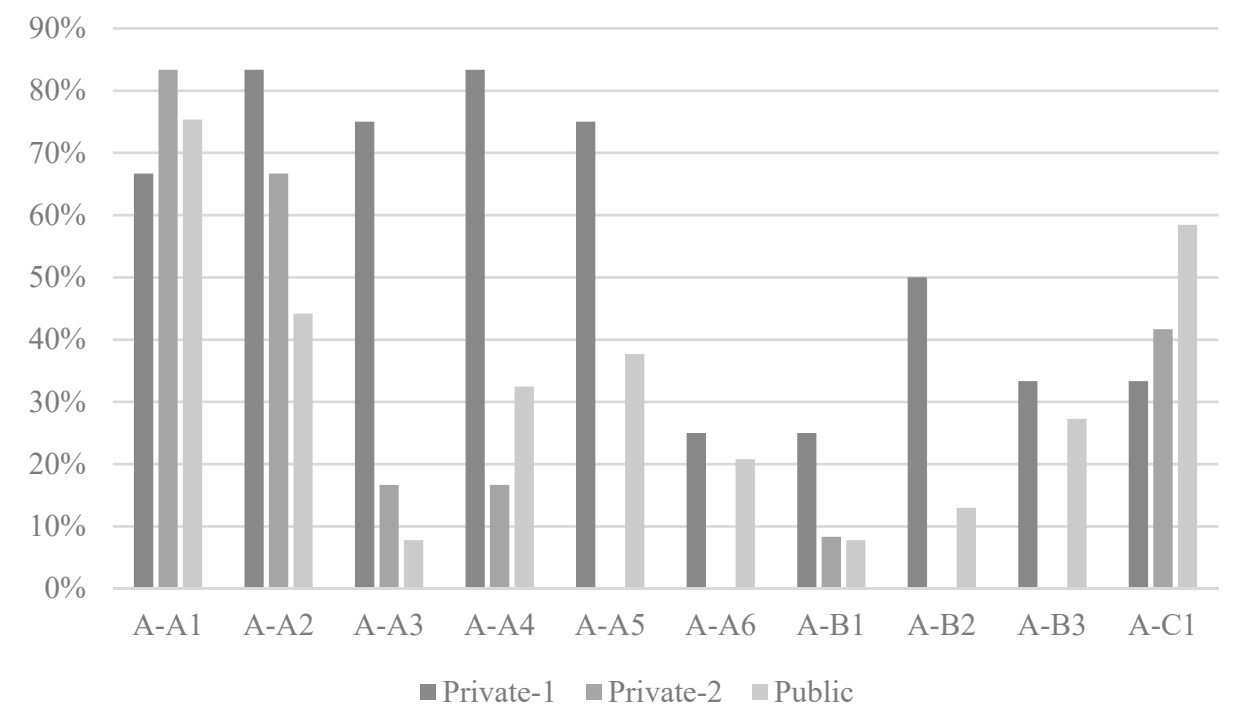

Figure 5. Relative contribution of each type of anomaly for the degradation of VLF in each type of inspected health facility.

Considering the age of Private-1 floorings, in most cases it had a greater incidence of anomalies. In fact, when visiting Private-1 facility, a need for major repair works was detected, in view of the high number of anomalies. Moreover, inspected Private-1 floorings were exclusively in linoleum. That explains the high relative frequency of anomaly "A-A4 prickles/punctures", associated with the greater residual indentation of the material and natural ageing. As for "A-A3 brightness changes", it was confirmed in situ that the high relative frequency is due to inadequate maintenance.

Compared with inspected Public infrastructures, Private-2 floorings had a higher incidence of "A-A1 scratches/wear", and the group of private infrastructures floorings had a higher incidence of 
"A-A2 staining/dirt/color changes", "A-A3 brightness changes", "A-A4 prickles/punctures", "A-B1 blistering", and "A-B2 peeling".

\subsection{Probable Causes of Anomalies}

The frequency of probable causes is shown in Figure 2. During the inspection program, causes C-A1, C-A2, and C-A4 (design errors), most "C-B execution errors" causes (except for C-B4 and C-B5), and cause "C-D1 sun exposure" were never observed, or observed only once. This is probably due to the lack of information on the design and execution stages, specifically about application conditions and methodologies used. It results in the difficult establishment of relationships between design and execution causes and anomalies in VLF more than one year old. Cause "C-C4 dragging of equipment" was the most frequent, as was indicated in approximately $28 \%$ of anomalies, probably due to a close correlation with the occurrence of scratches (A-A1).

The relative frequency of each of group of causes in the sample (Figure 6) shows that "C-C external mechanical actions" (46\%) and "C-D environmental actions" (26\%) were the ones that contribute the most to the occurrence of anomalies. In fact, each anomaly was caused by 0.72 mechanical actions, on average.

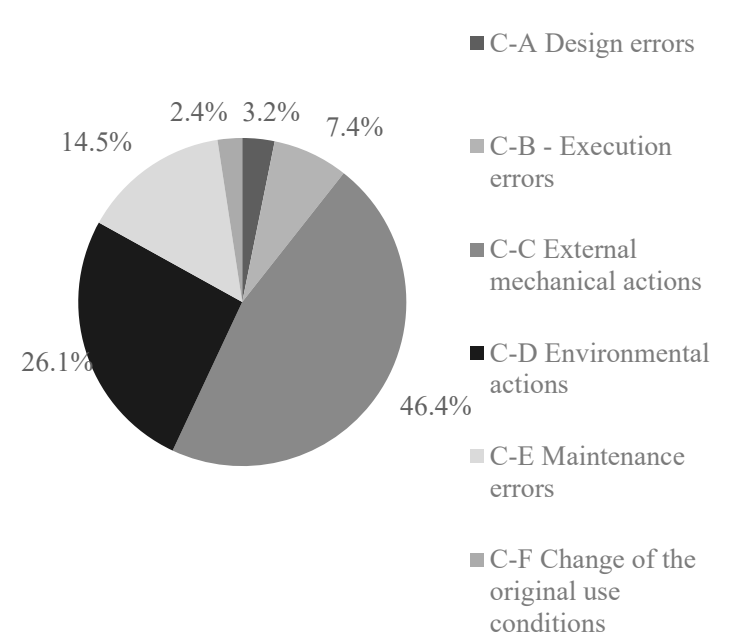

(a)

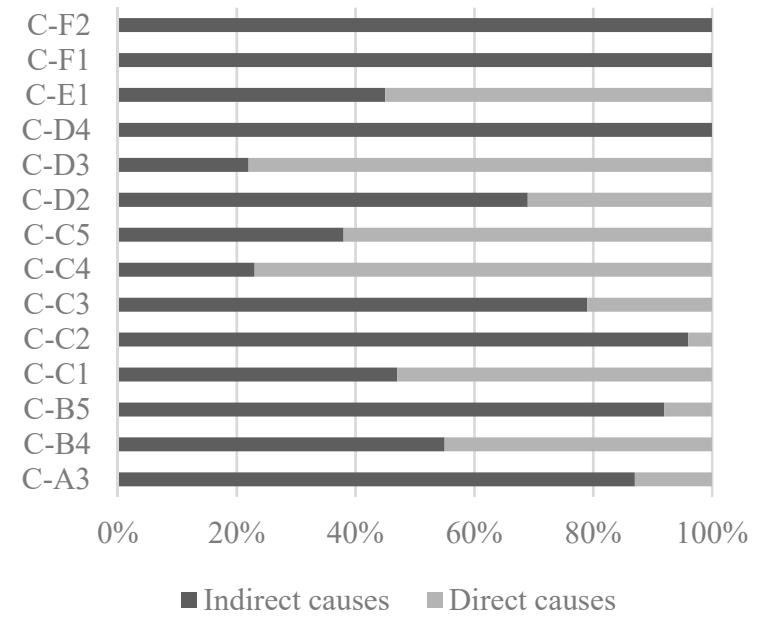

(b)

Figure 6. Probable causes of anomalies: (a) Relative frequency of each group of causes; and (b) direct vs. indirect causes.

In Figure 6, the distribution of causes in direct and indirect causes is shown, not considering causes with two occurrences or less. The causes most often identified as direct were "C-D3 presence of moisture" (78\%) and "C-C4 dragging of equipment" (77\%). On the other hand, the causes most frequently identified as indirect (in this case, with a frequency of $100 \%$ ) were "C-D4 natural ageing", "C-F1 excessive loads", and "C-F2 changing the use of space".

To analyze the contribution of each group of causes to each anomaly, Figure 7 was drawn. As to anomaly "A-A4 prickles/punctures", it resulted almost entirely from causes in group "C-C external mechanical actions" (on average, 1.51 causes per anomaly), and, within the group, the most influential causes were "C-C1 fall of objects" (81\%) and "C-C5 punching actions" (68\%). The latter occurs because furniture, like chairs and tables, have worn or absent protections. Punching may also be related with the accidental fall of objects, such as oxygen bottles. 


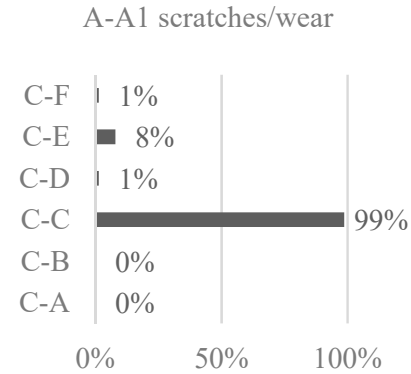

(a)

A-A4 prickles/punctures

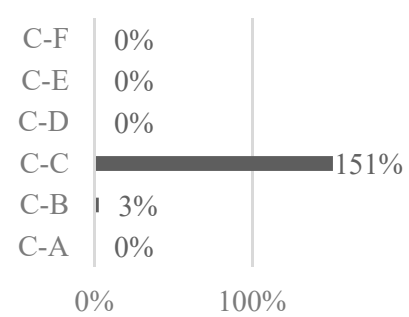

(d)

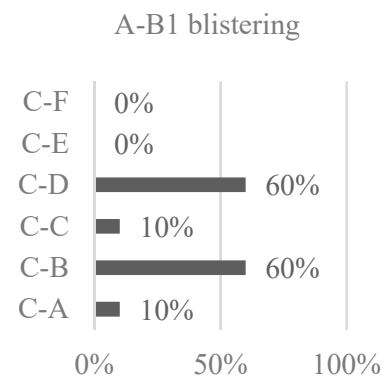

(g)

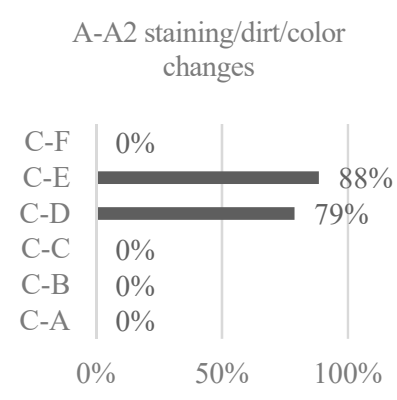

(b)

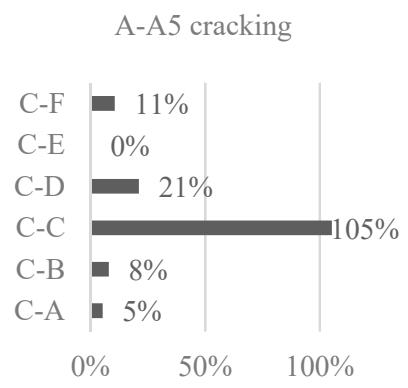

(e)

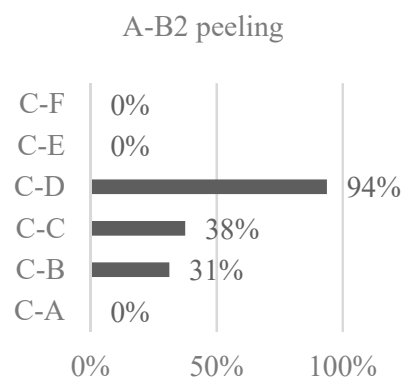

(h)
A-A3 brightness changes

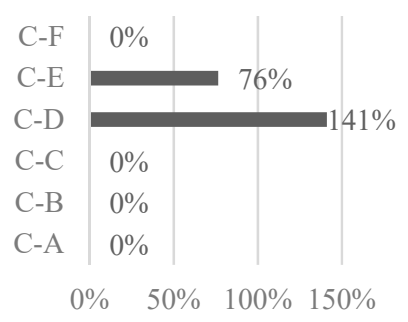

(c)

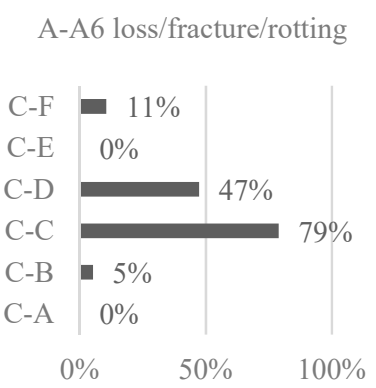

(f)

A-B3 depression/settlement

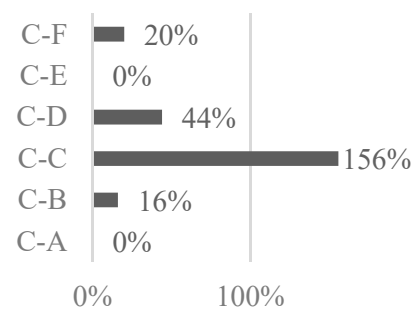

(i)

A-C1 faulty welding joints

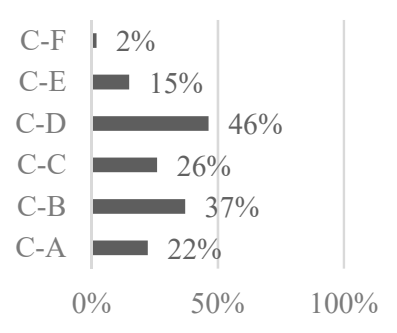

(j)

Figure 7. Contribution of each group of causes to each type of anomaly in the sample: (a) A-A1 scratches/wear; (b) A-A2 staining/dirt/color changes; (c) A-A3 brightness changes; (d) A-A4 prickles/ punctures; (e) A-A5 cracking; (f) A-A6 loss/fracture/rotting; (g) A-B1 blistering; (h) A-B2 peeling; (i) A-B3 depression/settlement; (j) A-C1 faulty welding joints.

As for anomalies "A-A2 staining/dirt/color changes" and "A-A3 brightness changes", they resulted exclusively from causes in groups "C-D environmental actions" and "C-E maintenance errors", the latter represented only by "C-E1 insufficient/incorrect cleaning of the flooring". In both A-A2 and $\mathrm{A}-\mathrm{A} 3$, the predominant environmental causes were "C-D2 biological action/chemically aggressive agents" ( $50 \%$ and $94 \%$, respectively) and "C-D4 natural ageing" ( $21 \%$ and $47 \%$, respectively). Such frequencies were expected, as the use of inappropriate cleansers or spilling of aggressive substances, 
such as antiseptic drugs, causes blemishes, changes in brightness, or indelible stains. Comparing these relationships with those in wood floorings, staining and color changes were mainly related with an inadequate finishing, natural ageing, and poor maintenance works [33]. So, only natural ageing was identified in both types of flooring, as the expected wear signs in floorings can only normally be eliminated with large investment (major repair works or replacement).

Anomaly "A-A1 scratches/wear" was almost exclusively influenced by group "C-C external mechanical actions" (99\%), due solely to "C-C4 dragging of equipment" (a direct cause). This cause represents the use of improper wheel material, which easily leaves a mark in VLF, or moving of furniture without adequate protections. In wood floorings [33], the circulation on floorings is also identified in all scratch's anomalies.

Anomaly "A-A5 cracking" was strongly influenced by the group of causes "C-C external mechanical actions", and, within this group, the most influential causes were "C-C3 substrate deformation" (50\%), "C-C2 concentration of stress in the substrate" $(34 \%)$, and "C-C4 dragging of equipment" (18\%). When deformation occurs on the substrate, such as depression, the VLF follows the deformation shape. Over time, the VLF loses flexibility and ends up cracking in the uneven zone.

Concerning anomaly "A-A6 loss/fracture/rotting", it was influenced by "C-D environmental actions" (47\%), specifically by causes "C-D3 presence of moisture" (37\%) and "C-D4 natural ageing" (11\%). But "C-C external mechanical actions" had an even stronger influence on anomaly A-A6 (79\%).

As for anomalies on the substrate, "A-B1 blistering", "A-B2 peeling", and "A-B3 depression/settlement", they were all influenced by "C-D environmental actions" (60\%, $94 \%$, and $44 \%$, respectively). Once more, the only influential causes of group C-D were "C-D3 presence of moisture" and "C-D4 natural ageing". Group "C-B execution errors" also had a strong influence on anomalies A-B1 (60\%) and A-B2 (31\%), whereas group "C-C external mechanical actions" had a strong influence on anomalies A-B2 (38\%) and A-B3 (1.56 causes per anomaly, on average). Hence, the two main causes of substrate anomalies were moisture and natural ageing of the VLF allied with execution errors and mechanical actions, such as stress concentration in the substrate.

Finally, anomaly "A-C1 faulty welding joints" was influenced by all groups of causes, although group "C-F change of the original use conditions" was only identified once. It is an expected result, as joints can easily be degraded if incorrectly designed, executed, submitted to mechanical actions and aggressive agents, or poorly maintained. A similar variety of types of causes may be verified in wood floorings' [33] defects in joints (change of joint size).

\subsection{Diagnosis Methods}

The absolute and relative frequencies of the diagnosis methods identified in the sample are shown in Figure 2. It should be noted that, by default, all anomalies were associated with the diagnosis method "M-A1 visual inspection". The most frequent method, not considering M-A1, was "M-A3 crack ruler", adequate to $43 \%$ of the anomalies, probably due to its easy use in superficial anomalies and joints. The least chosen method was "M-D3 hygrometer" (seven cases), which may be related with the legal requirements, in terms of ambient moisture content, healthcare infrastructures are subjected to. Comparing with diagnosis methods that were found adequate for anomalies in wood floorings, moisture measurement was much more recommended (almost in 30\% of anomalies), as vinyl floorings are not so sensitive to dampness and the wood floorings sample did not include healthcare infrastructures [33].

The frequency of the diagnosis methods recommended for each anomaly is shown in Figure 8. Anomaly "A-A1 scratches/wear" was only associated with methods "M-A1 visual inspection" (100\%) and "M-A3 crack ruler" (97\%), as expected. By measuring the thickness of the scratch, one can more easily diagnose the probable cause of the anomaly. While dragging of equipment generally causes a finer scratch, the movement of inadequate cart wheels leaves a thicker scratch. Anomalies "A-A2 staining/dirt/color changes", and "A-A3 brightness changes" were exclusively associated with method M-A1. 


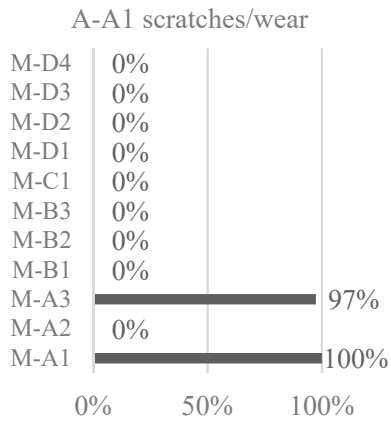

(a)

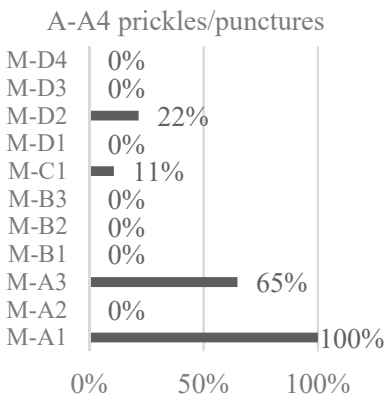

(d)

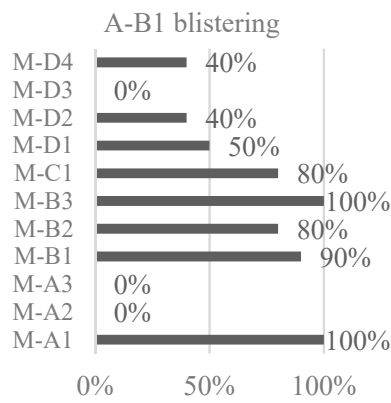

(g)

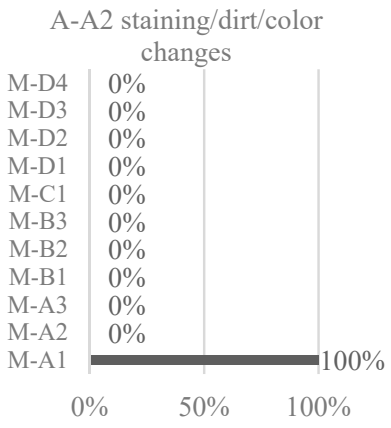

(b)

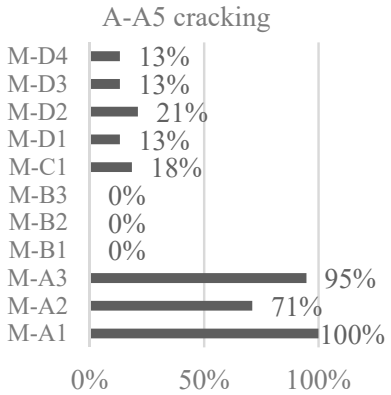

(e)

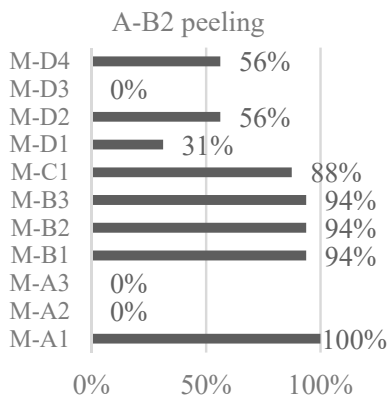

(h)

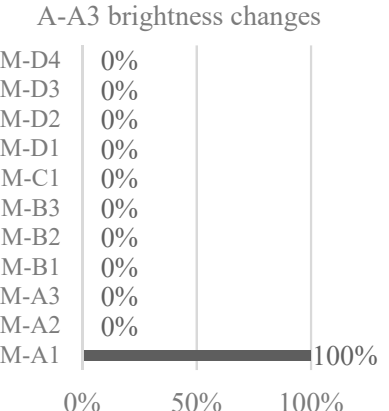

(c)

A-A6 loss/fracture/rotting

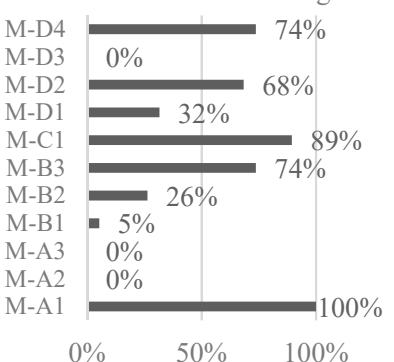

(f)

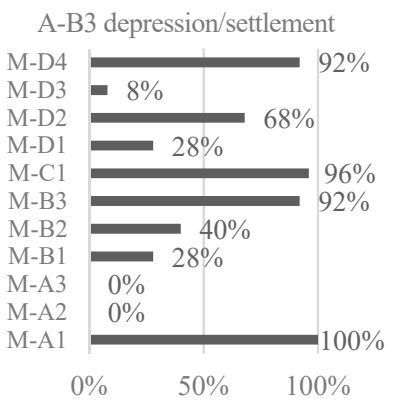

(i)

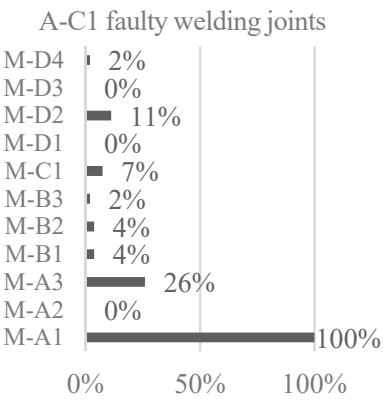

(j)

Figure 8. Contribution of each diagnosis method to each type of anomaly in the sample: (a) A-A1 scratches/wear; (b) A-A2 staining/dirt/color changes; (c) A-A3 brightness changes; (d) A-A4 prickles/ punctures; (e) A-A5 cracking; (f) A-A6 loss/fracture/rotting; (g) A-B1 blistering; (h) A-B2 peeling; (i) A-B3 depression/settlement; (j) A-C1 faulty welding joints.

As for anomaly "A-A4 prickles/punctures", aside from method M-A1, methods "M-A3 crack ruler" (65\%), "M-D2 superficial moisture measurement" (22\%), and "M-C1 infrared thermography" 
$(11 \%)$ were recommended. These results were expected, since the crack ruler may assist in measuring the anomaly, while measuring moisture may show changes in moisture content, whose causes and extent may be better determined with infrared thermography.

Anomaly "A-A5 cracking" was strongly associated with methods "M-A2 crack meter" (71\%) and "M-A3 crack ruler" (95\%), aside from M-A1. These tools, allied with the visual inspection, were the best at diagnosing this type of anomaly. A-A 5 was also characterized by a weak relationship with all other methods, except for mechanical methods (M-B).

For anomaly "A-A6 loss/fracture/rotting", diagnosis methods "M-A1 visual inspection" (100\%), "M-B3 pull-off adhesion test" (74\%), "M-C1 infrared thermography (89\%), "M-D2 superficial moisture measurement" (68\%), and "M-D4 speedy moisture test" (16\%) were strongly recommended to better assess its causes.

Regarding anomalies on the substrate, "A-B1 blistering", "A-B2 peeling", and "A-B3 depression/ settlement" were all associated with diagnosis methods "M-B1 sphere impact test", "M-B2 percussion hammer", "M-B3 pull-off adhesion test", "M-C1 infrared thermography", "M-D1 inner moisture and temperature measurement", "M-D2 superficial moisture measurement" and "M-D4 speedy moisture test", besides method "M-A1 visual inspection". For anomaly A-B1, methods M-B3 (100\%) and M-B1 (90\%) should be highlighted as they were advised in circumstances in which the adhesion conditions have changed. As for anomaly A-B2, diagnosis methods M-B1, M-B2, and M-B3 were equally recommended in $94 \%$ of detected cases. For anomaly A-B3, methods M-C1 (96\%), M-B3 (92\%), and M-D4 (92\%) were the most recommended, given the probable association of A-B3 with dampness and the usefulness of determining adhesion conditions.

Finally, anomaly "A-C1 faulty welding joints" was mostly associated with method "M-A1 visual inspection", but "M-A3 crack ruler" (26\%) may also play an important role in determining the size of the joint and of any detected cracks in its welding.

\subsection{Repair Techniques}

The absolute and relative frequencies of repair techniques were analyzed (Figure 2). On the one hand, the most advised technique was "R-A1 cleaning the cladding", recommended for approximately $49 \%$ of detected anomalies, which can be due to its immediate effect on the aesthetic value of the affected area. On the other hand, technique "R-B3 glue injection", was the least chosen (three cases), which is probably associated with being only advised in special circumstances of anomaly "A-B1 blistering". In wood floorings [33], the injection of voids with resin was also not recommended for many of the detected anomalies. Specific repair works do not tend to be used frequently, regardless of the flooring material.

Concerning the frequency of suggested repair techniques for each anomaly (Figure 9), "A-A5 cracking", "A-A6 loss/fracture/rotting", "A-B2 peeling", and "A-B3 depression/settlement" were highly associated with repair technique "R-B2 partial replacement of the flooring", as it was considered in more than $60 \%$ of anomalies of these types. Anomalies "A-A1 scratches/wear", "A-A2 staining/dirt/color changes", and "A-A3 brightness changes" were associated with repair technique "R-A2 applying a surface protector" in more than $75 \%$ of the cases.

Anomaly "A-A1 scratches/wear" should be repaired by "R-A1 cleaning the cladding" (96\%) and "R-A2 applying a surface protector" (87\%), to reduce its aesthetic impact by smoothing the surface. As stripping (R-A3) is exclusively used in linoleum floorings, it has a small incidence in the sample (12\%), since, in the inspection campaign, only 13 of 101 analyzed floorings were linoleum. When A-A1 occurs, partial (R-B2) or total replacement (R-B1) only should take place when the area has a high aesthetic value, hence these techniques were only scarcely recommended in this context. 


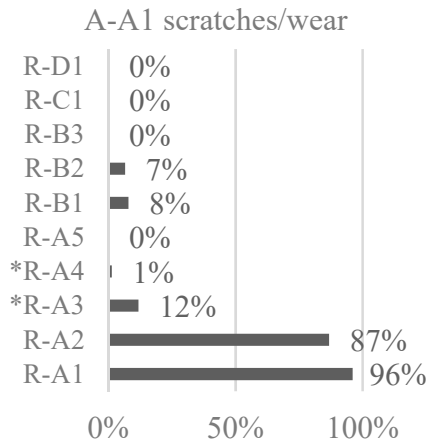

(a)

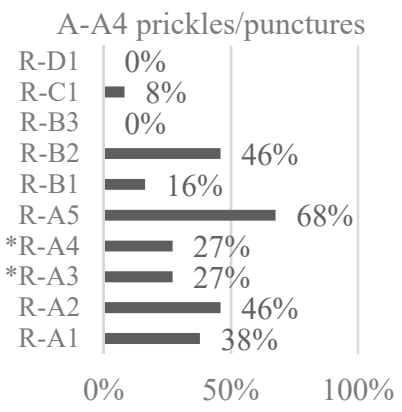

(d)

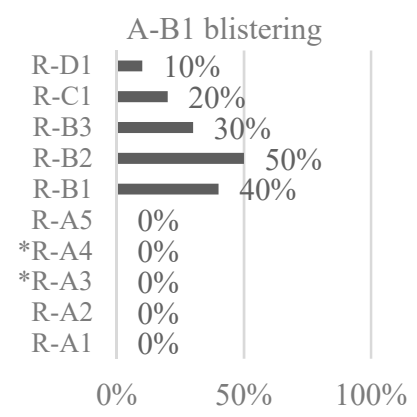

(g)

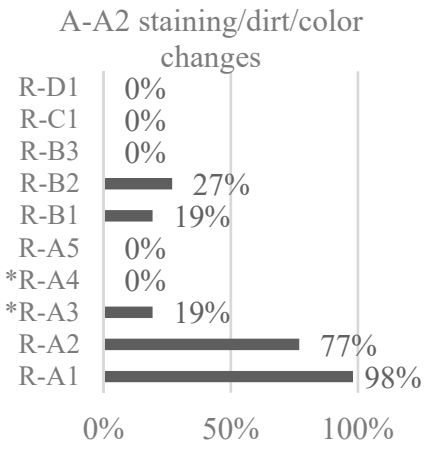

(b)

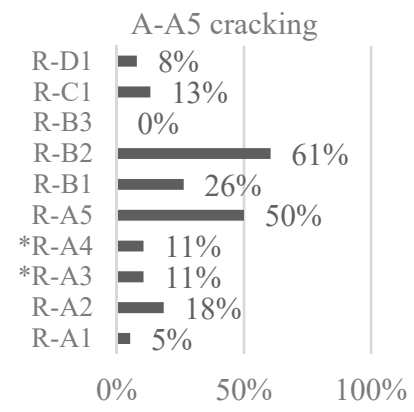

(e)

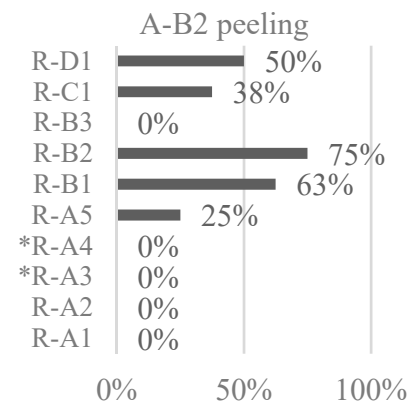

(h)

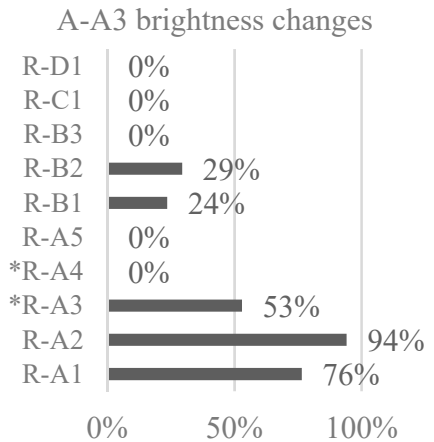

(c)

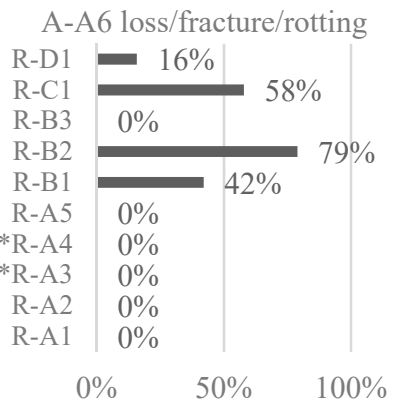

(f)

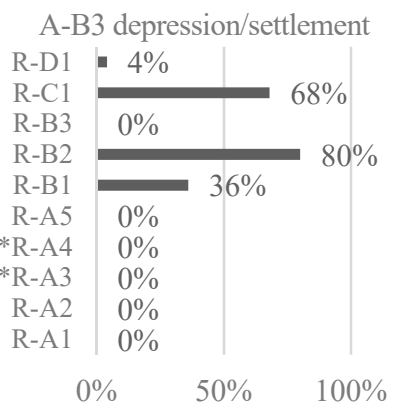

(i)

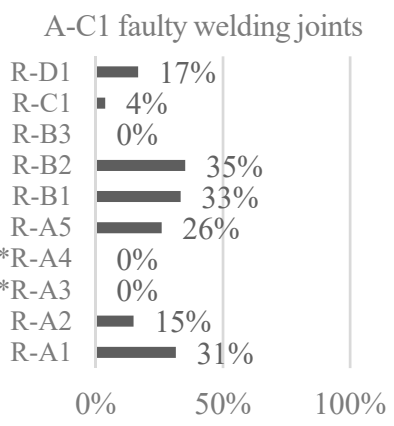

(j)

Figure 9. Contribution of each repair technique to each type of anomaly in the sample: (a) A-A1 scratches/wear; (b) A-A2 staining/dirt/color changes; (c) A-A3 brightness changes; (d) A-A4 prickles/ punctures; (e) A-A5 cracking; (f) A-A6 loss/fracture/rotting; (g) A-B1 blistering; (h) A-B2 peeling; (i) A-B3 depression/settlement; (j) A-C1 faulty welding joints.

Anomalies "A-A2 staining/dirt/color changes" and "A-A3 brightness changes" were both repaired by "R-A1 cleaning the cladding" ( $98 \%$ and $76 \%$, respectively), "R-A2 applying a surface protector" 
(77\% and 94\%), "R-A3 stripping" (19\% and 53\%), "R-B1 total replacement of the flooring" (19\% and $24 \%)$, and "R-B2 partial replacement of the flooring" (27\% and $29 \%$, respectively). Although the inspected rooms were in health facilities, and the cleaning requirements were extremely high, the results on the replacement techniques were acceptable, since most A-A2 and A-A3 anomalies were stains, discoloration, and brightness changes with some aesthetic value, but not accumulated dirt. As for stripping (R-A3), in linoleum floorings, it was less associated with stains than with brightness changes. It was noticed that floorings were cleaned and waxed regularly, but stripping was only partial and not in the required timings, often resulting in alternated areas with different wax thicknesses, as seen in Figure $4 \mathrm{~d}$.

Anomaly "A-A4 prickles/punctures" was only not associated with repair techniques R-B3 and R-D1. The application of the remaining seven repair techniques depends on the area affected by the anomaly. For small areas, cleaning (R-A1) and applying a sealant (R-A2) or a weld bead was sufficient (R-A5). In the case of a linoleum flooring, it can be stripped (R-A3), or the punctures can be covered with a mixture of white glue and linoleum scraps (R-A4).

Anomaly "A-A5 cracking" was mostly associated with repair techniques "R-A5 application of welding" (50\%), "R-B1 total replacement of the flooring" (26\%), and "R-B2 partial replacement of the flooring" (61\%). The use of these techniques depends on the anomaly's depth, width, and affected area.

As for anomaly "A-A6 loss/fracture/rotting", techniques "R-B1 total replacement of the flooring" $(42 \%)$ and "R-B2 partial replacement of the flooring" (79\%) were repeatedly recommended, as well as "R-C1 replacement of the levelling layer" (58\%), the latter acting on the causes of the defect.

Regarding the anomalies on the substrate, "A-B1 blistering", "A-B2 peeling", and "A-B3 depression/ settlement" may all be repaired by techniques "R-B1 total replacement of the flooring", "R-B2 partial replacement of the flooring", "R-C1 replacement of the levelling layer", and "R-D1 repair of anomalies in footers", or skirting. Anomaly A-B1 may also be repaired with "R-B3 glue injection" (30\%), which is used in specific cases of blistering. This happens especially when, in the months following the application, it is found that the blistered area has no glue and consists of a small extent, as seen in Figure 4e. As for anomaly A-B2, in 25\% of the cases it could also be repaired by "R-A5 application of welding". In addition, A-B2 is the type of anomaly most associated with repair technique R-D1, in relative terms (50\% of the cases). In order to be well laid, the VLF must be heated, to become flexible and follow the curve of the cove former, and then compressed, to ensure adhesion. This process may be difficult, as the surface is not smooth or horizontal. If these steps are not carefully followed, the detachment of the coving may occur.

Anomaly A-B3 may occur both in small and large areas, influencing the choice of repair techniques R-B1 (36\%) or R-B2 (80\%). Figure $4 \mathrm{f}$ illustrates a corridor, where the constant passage of trolleys and a possible poor levelling layer caused depressions, which later evolved to cracks.

Finally, anomaly "A-C1 faulty welding joints" may be repaired by all techniques except R-A3, R-A4, and R-B3. The most commonly recommended techniques were "R-A1 cleaning the cladding" $(31 \%)$, "R-A5 application of welding" (26\%), "R-B1 total replacement of the flooring" (33\%), and "R-B2 partial replacement of the flooring" (35\%).

\section{Conclusions}

The gathered data, based on a significant sample of 101 vinyl and linoleum floorings, enabled the validation of the classification system of anomalies, probable causes, in situ diagnosis methods, and repair techniques for vinyl and linoleum floorings, as well as each correlation matrix proposed by Carvalho et al. [19].

The main problems detected in VLF consisted of scratches, staining, color changes, some dirt, and anomalies on the joints, which were detected in more than a half of the inspected floorings. Accordingly, the dragging of equipment and the incorrect cleaning of the flooring were frequently identified as causes of anomalies in VLF. To assist the diagnosis of detected anomalies, the use of a crack ruler was found useful for its versatility, including the measurement of scratches. To correct the 
detected defects, cleaning, applying a surface protector, and even partially replacing the flooring were frequently recommended. It is essential to train cleaning companies, since inadequate maintenance directly contributes to accelerate the degradation of VLF. It is also necessary to ensure the quality control of the application of VLF through regular inspections and skilled manpower.

In the sample of inspected healthcare facilities, most detected anomalies have an average urgency of repair. However, a significant percentage of anomalies were still considered in need of urgent repair. In absolute terms, anomalies "A-A5 cracking" and "A-C1 faulty welding joints" present the highest number of cases in level 0 of urgency of repair, although, in relative terms, a higher percentage of cases of "A-B2 peeling" in level 0 was detected.

Considering the private and public healthcare facilities samples, in relative terms, all types of anomalies show a higher relative frequency in private facilities, except for "A-C1 faulty welding joints", detected in higher percentage in public healthcare facilities. In the inspected private facilities, "A-A1 scratches/wear", "A-A2 staining/dirt/color changes", and "A-A4 prickles/punctures" were the most frequently detected. In public facilities, anomaly A-A1 was also detected in the most relevant number of floorings.

This paper contributes to the dissemination of knowledge on the degradation of VLF, specifically in health infrastructures. With the presented data in mind, maintenance plans may be improved and more effective. Data may also be useful, for instance, at the design stage, as future defects, such as those caused by dragging, may be prevented if the type of vinyl or linoleum flooring is adequately chosen, restricting the functional requirements to more demanding ones. Additionally, at the design stage, a maintenance manual or a concise user's manual for the building may be developed and delivered to the client. That measure may potentially improve maintenance operations, such as cleaning. At the application stage, several measures may be implemented to avoid defects, always starting with the use of specialized labor and better communication between contractors. Specialized labor is more likely to apply floorings according to the best practices, hence avoiding defects caused by execution errors. As for communication between contractors, it may contribute, for instance, to an adequate substrate preparation, according to the requirements for VLF. It is also expected that the efficiency and effectiveness of maintenance in VLF increases if the inspection system proposed by Carvalho et al. [19] is used. In the future, to improve the system, a wider inspections campaign should be made.

Author Contributions: Conceptualization, J.d.B.; methodology, J.d.B. and I.F.-C.; formal analysis, C.C. and C.P.; investigation, C.C.; resources, C.C.; writing-original draft preparation, C.C.; writing-review and editing, C.P. and J.d.B.; visualization, C.C. and C.P.; supervision, J.B. and I.F.-C.

Funding: This research received no external funding.

Acknowledgments: The authors gratefully acknowledge the support of the CERIS Research Institute; IST, University of Lisbon; and FCT, Foundation for Science and Technology.

Conflicts of Interest: The authors declare no conflicts of interest. The funders had no role in the design of the study; in the collection, analyses, or interpretation of data; in the writing of the manuscript, or in the decision to publish the results.

\section{References}

1. Douglas, J.; Noy, E.A. Building Surveys and Reports, 4th ed.; Wiley-Blackwell: Chichester, UK, 2011; pp. $203-204$.

2. Dejaco, M.C.; Re Cecconi, F.; Maltese, S.; Spagnolo, S.L.; Kamara, J.M. Requirements compliance checking for existing buildings. In Proceedings of the CIB World Building Congress, Tampere, Finland, 30 May-3 June 2016; pp. 706-718.

3. Aktas, C.B.; Bilec, M.M. Service life prediction of residential interior finishes for life cycle assessment. Int. J. Life Cycle Assess. 2012, 17, 362-371. [CrossRef]

4. $\quad$ CIB W86. Building Pathology: A State-of-the-Art Report; CIB: Delft, The Netherlands, 1993.

5. Dixit, M.K.; Singh, S.; Lavy, S.; Yan, W.; Pariafsai, F.; Ostadalimakhmalbaf, M. Floor finish selection in the design of healthcare facilities: A survey of facility managers. Facilities 2019. [CrossRef] 
6. ASTM E96/E96M-16. Standard Test Methods for Water Vapor Transmission of Materials; ASTM International: West Conshohocken, PA, USA, 2016.

7. ASTM E1745-17. Standard Specification for Plastic Water Vapor Retarders Used in Contact with Soil or Granular Fill under Concrete Slabs; ASTM International: West Conshohocken, PA, USA, 2017.

8. ASTM F710-17. Standard Practice for Preparing Concrete Floors to Receive Resilient Flooring; ASTM International: West Conshohocken, PA, USA, 2017.

9. ASTM F1482-15. Standard Practice for Installation and Preparation of Panel Type Underlayments to Receive Resilient Flooring; ASTM International: West Conshohocken, PA, USA, 2015.

10. ASTM F1516-13. Standard Practice for Sealing Seams of Resilient Flooring Products by the Heat Weld Method (When Recommended); ASTM International: West Conshohocken, PA, USA, 2013.

11. ASTM F1869-16a. Standard Test Method for Measuring Moisture Vapor Emission Rate of Concrete Subfloor Using Anhydrous Calcium Chloride; ASTM International: West Conshohocken, PA, USA, 2016.

12. ASTM F1913-04. Standard Specification for Vinyl Sheet Floor Covering without Backing; ASTM International: West Conshohocken, PA USA, 2014.

13. ASTM F2170-17. Standard Test Method for Determining Relative Humidity in Concrete Floor Slabs Using In Situ Probes; ASTM International: West Conshohocken, PA, USA, 2017.

14. ACI 117-10. Specification for Tolerances for Concrete Construction and Materials; ACI Committee 117; American Concrete Institute: Farmington Hills, MI, USA, 1990.

15. ACI 223R. Standard Practice for the Use of Shrinkage-Compensating Concrete; ACI Committee 223; American Concrete Institute: Farmington Hills, MI, USA, 2010.

16. ACI 302.1R. Guide for Concrete Floor and Slab Construction; ACI Committee 302; American Concrete Institute: Farmington Hills, MI, USA, 2015.

17. ACI 302.2R. Guide for Concrete Slabs that Receive Moisture-Sensitive Flooring Materials; ACI Committee 302; American Concrete Institute: Farmington Hills, MI, USA, 2006.

18. ACI 360R. Guide to Design of Slabs-on-Ground; ACI Committee 360; American Concrete Institute: Farmington Hills, MI, USA, 2010.

19. Carvalho, C.; de Brito, J.; Flores-Colen, I.; Pereira, C. Inspection, diagnosis and rehabilitation system for vinyl and linoleum floorings in health infrastructures. J. Perform. Constr. Facil. 2018, 32, 04018078. [CrossRef]

20. Lent, T.; Silas, J.; Vallete, J. Chemical hazards analysis of resilient flooring for healthcare. HERD-Health Environ. Res. 2010, 3, 97-117. [CrossRef]

21. Carling, P.C.; Bartley, J.M. Evaluating hygienic cleaning in health care settings: What you do not know can harm your patients. Am. J. Infect. Control 2010, 38, S41-S50. [CrossRef]

22. Brito, F. Controlo da contaminação de superfícies no meio hospitalar (Contamination control of surfaces in the hospital environment). TecnoHospital 2017, 79, 10-11. (In Portuguese)

23. Toreki, W.; Kanga, R.S. Regeneration of Antimicrobial Coatings Containing Metal Derivates upon Exposure to Aqueous Hydrogen Peroxide. U.S. Patent 9,549,547 B2, 24 January 2017.

24. Harris, D.D.; Pacheco, A.; Lindner, A.S. Detecting potential pathogens on hospital surfaces: An assessment of carpet tile flooring in the hospital patient environment. Indoor Built Environ. 2010, 19, 239-249. [CrossRef]

25. Harris, D.D.; Detke, L.A. The role of flooring as a design element affecting patient and healthcare worker safety. HERD-Health Environ. Res. 2013, 6, 95-119. [CrossRef]

26. Harris, D.D.; Fitzgerald, L. A life-cycle cost analysis for flooring materials for healthcare facilities. J. Hosp. Adm. 2013, 4, 92-100. [CrossRef]

27. Schwartz, P.H.; Wesselschmidt, R.L. Essential requirements for setting up a stem cell laboratory. In Stem Cell Technologies in Neuroscience; Srivastava, A., Snyder, E., Teng, Y., Eds.; Humana Press: New York, NY, USA, 2017; pp. 225-237.

28. Ayçam, I.; Yazici, A. Evaluation of operating room units within the context of green design criteria. GU J. Sci. 2017, 30, 1-15.

29. Heisterberg-Moutsis, G.; Heinz, R.; Wolf, T.F.; Harper, D.J.; James, D.; Mazzur, R.P.; Kettler, V.; Soiné, H.; Peoples, R. Floor coverings. In Ullmann's Encyclopaedia of Industrial Chemistry; Wiley-VCH Verlag GmbH \& Co. KGaA: Weinheim, Germany, 2017. [CrossRef]

30. Harris, D.D. A material world: A comparative study of flooring material influence on patient safety, satisfaction, and quality of care. J. Interior Des. 2017, 42, 85-104. [CrossRef] 
31. Amaro, B.; Saraiva, D.; de Brito, J.; Flores-Colen, I. Statistical survey of the pathology, diagnosis and rehabilitation of ETICS in walls. J. Civ. Eng. Manag. 2014, 20, 511-526. [CrossRef]

32. Conceição, J.; Poça, B.; de Brito, J.; Flores-Colen, I.; Castelo, A. Data analysis of inspection, diagnosis, and rehabilitation of flat roofs. J. Perform. Constr. Facil. 2019, 33, 04018100. [CrossRef]

33. Delgado, A.; Pereira, C.; de Brito, J.; Silvestre, J.D. Defect characterization, diagnosis and repair of wood flooring based on a field survey. Mater. Constr. 2018, 68,1-13. [CrossRef]

34. Gaião, C.; de Brito, J.; Silvestre, J. Technical note: Gypsum plasterboard walls: Inspection, pathological characterization and statistical survey using an expert system. Mater. Constr. 2012, 62, 285-297. [CrossRef]

35. Garcez, N.; Lopes, N.; de Brito, J.; Silvestre, J. Pathology, diagnosis and repair of pitched roofs with ceramic tiles: Statistical characterisation and lessons learned from inspections. Constr. Build. Mater. 2012, 36, 807-819. [CrossRef]

36. Neto, N.; de Brito, J. Validation of an inspection and diagnosis system for anomalies in natural stone cladding (NSC). Constr. Build. Mater. 2012, 30, 224-236. [CrossRef]

37. Pereira, A.; Palha, F.; de Brito, J.; Silvestre, J.D. Diagnosis and repair of gypsum plaster coatings: Statistical characterization and lessons learned from a field survey. J. Civ. Eng. Manag. 2010, 20, 485-496. [CrossRef]

38. Pires, R.; de Brito, J.; Amaro, B. Statistical survey of the inspection, diagnosis and repair of painted rendered façades. Struct. Infrastruct. E 2015, 11, 605-618. [CrossRef]

39. Sá, G.; Sá, J.; de Brito, J.; Amaro, B. Statistical survey on inspection, diagnosis and repair of wall renderings. J. Civ. Eng. Manag. 2015, 21, 623-636. [CrossRef]

40. Santos, A.; Vicente, M.; de Brito, J.; Flores-Colen, I.; Castelo, A. Analysis of the inspection, diagnosis, and repair of external door and window frames. J. Perform. Constr. Facil. 2017, 31, 04017098. [CrossRef]

41. Da Silva, C.; Coelho, F.; de Brito, J.; Silvestre, J.; Pereira, C. Statistical Survey on Inspection, Diagnosis, and Repair of Architectural Concrete Surfaces. J. Perform. Constr. Facil. 2017, 31, 04017097. [CrossRef]

42. Silvestre, J.D.; de Brito, J. Inspection and repair of ceramic tiling within a building management system. J. Mater. Civ. Eng. 2010, 22, 39-48. [CrossRef]

43. Gorrée, M.; Guinée, J.B.; Huppes, G.; Oers, L.V. Environmental life cycle assessment of linoleum. Int. J. Life Cycle Assess. 2002, 7, 158-166. [CrossRef]

44. Personen-Leinonen, E.; Redsven, I.; Neuvonen, P.; Hurme, K.R.; Pääkkö, M.; Koponen, H.K.; Pakkanen, T.T.; Uusi Rauva, A.; Hautala, M.; Sjöberg, A.M. Determination of soil adhesion to plastic surfaces using a radioactive tracer. Appl. Radiat. Isotopes 2006, 64, 163-169. [CrossRef] 